\title{
Erratum to: Cancer outcomes and all-cause mortality in adults allocated to metformin: systematic review and collaborative meta-analysis of randomised clinical trials
}

\author{
R. J. Stevens • R. Ali • C. R. Bankhead • M. A. Bethel • B. J. Cairns • R. P. Camisasca • \\ F. L. Crowe - A. J. Farmer • S. Harrison • J. A. Hirst - P. Home • S. E. Kahn • \\ J. H. McLellan • R. Perera • A. Plüddemann - A. Ramachandran • N. W. Roberts • \\ P. W. Rose • A. Schweizer • G. Viberti • R. R. Holman
}

Published online: 18 October 2012

(C) Springer-Verlag Berlin Heidelberg 2012

\section{Erratum to: Diabetologia \\ DOI 10.1007/s00125-012-2653-7}

The authors regret a single data transcription error at the coordinating centre that resulted in numerical errors in several of the reported hazard ratios for all-cause mortality. The correct values (shown in red font) in the text should have been:

Abstract: The summary RR for all-cause mortality was 0.99 $(95 \%$ CI $0.83,1.17)$ across all trials.

Results, All-cause mortality: RRs for all-cause mortality could be obtained for 13 trials, representing 66,447

The online version of the original article can be found at http://dx.doi.org/ 10.1007/s00125-012-2653-7.

R. J. Stevens $(\bowtie) \cdot$ C. R. Bankhead · A. J. Farmer · S. Harrison •

J. A. Hirst · J. H. McLellan $\cdot$ R. Perera $\cdot$ A. Plüddemann •

N. W. Roberts $\cdot$ P. W. Rose

Department of Primary Care Health Sciences,

University of Oxford,

Woodstock Road,

Oxford OX2 6GG, UK

e-mail: richard.stevens@phc.ox.ac.uk

R. Ali $\cdot$ B. J. Cairns $\cdot$ F. L. Crowe

Cancer Epidemiology Unit, University of Oxford,

Oxford, UK

\section{A. Bethel • R. R. Holman}

Diabetes Trials Unit, Oxford Centre for Diabetes Endocrinology and Metabolism, University of Oxford,

Oxford, UK

R. P. Camisasca

TGRD Europe, Takeda Pharmaceutical Company,

London, UK

P. Home

ICM-Diabetes, The Medical School, Newcastle University,

Newcastle upon Tyne, UK person-years of follow-up during which 566 deaths were recorded. ... The summary RR for all-cause mortality in people randomised to metformin compared with all comparators was $0.99(95 \% \mathrm{CI} 0.83,1.17)$. The summary RR for all-cause mortality was $0.91(95 \%$ CI $0.70,1.18)$ in trials comparing metformin to placebo/usual care and 1.05 (95\% CI $0.84,1.33$ ) in trials comparing metformin to active comparators (Fig. 3). The summary RR from 1-year trials was $0.84(95 \% \mathrm{CI} 0.52,1.38)$ and the summary RR from trials longer than 1 year was $1.01(95 \%$ CI $0.84,1.22)$. In a post hoc sensitivity analysis, excluding the UKPDS

\section{S. E. Kahn}

Division of Metabolism, Endocrinology and Nutrition, Department of Medicine, Veterans Affairs Puget Sound Health Care System and University of Washington,

Seattle, WA, USA

\section{A. Ramachandran}

India Diabetes Research Foundation,

Dr A. Ramachandran's Diabetes Hospitals,

Egmore,

Chennai, India

\section{A. Schweizer \\ Novartis Pharma, \\ Basel, Switzerland}

G. Viberti

Unit for Metabolic Medicine, School of Medicine,

King's College London,

London, UK 


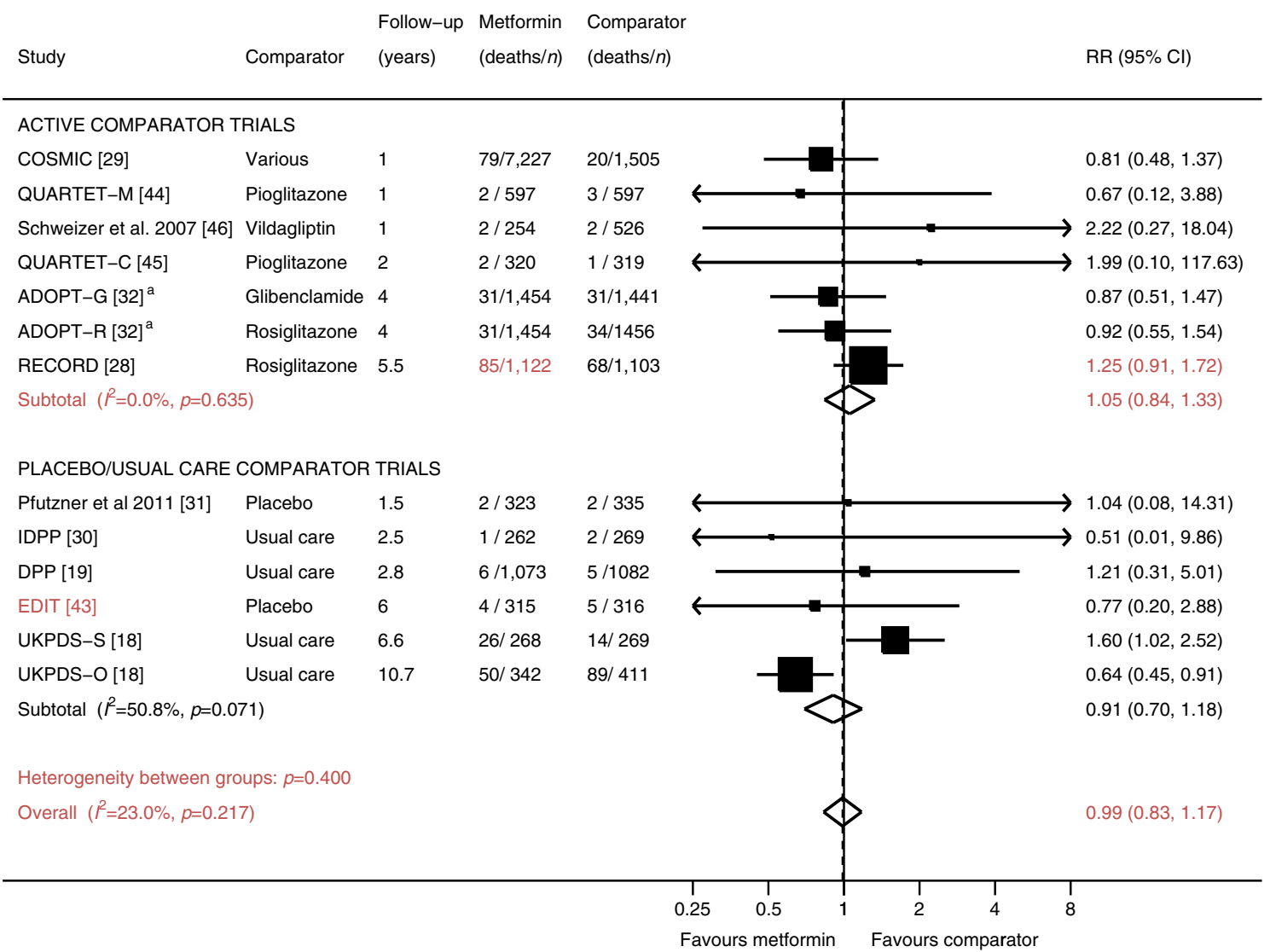

Fig. 3 RRs (squares) and 95\% CIs (horizontal bars) for all-cause mortality in participants in RCTs randomised to metformin compared with comparators, stratified by comparator type, with summary estimates and 95\% CIs (diamonds). ${ }^{a}$ Note that the ADOPT-G and ADOPT-R

sulfonylurea trial had the effect of reducing the RR for all-cause mortality in metformin compared with placebo/usual care to 0.67 (95\% CI $\left.0.49,0.93 ; \mathrm{I}^{2} 0.0 \%\right)$, and in metformin compared with any comparator to $0.91\left(95 \% \mathrm{CI} 0.75,1.10 ; \mathrm{I}^{2} 0.0 \%\right)$. lines represent multiple comparisons from a single trial, and the analysis takes account of correlation between these comparisons: see original text for details

A corrected version of Fig. 3 is shown above.

In addition, a typographical error appeared in Fig. 2. In the 'Study' column 'EDIT-A [43]' should have read 'EDIT [43]'. 